\section{INDO-OCEANIC RACES}

TWO papers of considerable interest on the peoples of the Pacific and Indian Islands were read at the last meeting of the Anthropological Institute. The first of these papers, by the Rev. S. J. Whitmee, so long resident in Samoa, was for the purpose of proposing a revised nomenclature of what he calls the Inter-Oceanic races of men. There is much confusion, it is admitted, in the use of geographical and ethnographical names in the Pacific. Polynesia is employed by some for all the intertropical islands eastward of New Guinea. By others it is used for those islands which are east of Fiji, while Melanesia is employed for the southern islands from Fiji westward, and Micronesia for the northern island. Mr. Whitmee proposes that Polynesia should be uniformly employed in the wider signification, and that the different portions be indicated by east, west, and north-west, just as we indicate the parts of a continent.

The term Inter.Oceanic Races is used for the people found in Madagascar, Australasia, the Indian Archipelago, Formosa, and Polynesia. In this region there are.two classes of people, who may be superficially described as dark and brozon.

The dark people comprise three very distinct races : I. The Australians, who may bear the name Australs; 2 . The people found in the Andaman Islands, the interior of the Malacca peninsula, and some portions of the Indian Archipelago, who already have a good name, viz., Negritos; 3 . The woolly-haired people of Western New Guinea, the Aru, and other islands in the Indian Archipelago, and Western Polynesia. Two names have been used for these-Papuan and Melanesian, and Mr. Whitmee proposes to keep Papuan and drop Melanesian. Where these Papuans are somewhat mixed with brown Poly nesian blood, they may be conveniently known as sub-Papuan.

The people known as Alfurese in the Indian Arcbipelago Mr. Whitmee does not regard as a separate people. As used by the Malays, Alfuro appears simply to mean non-Mabommedan and non-Christian-pagan wild men, whether brown or black. Hence Alfuro cannot be used as an ethnic appellation.

The brown people found, from Madagascar, through the Indian Archipelago, in Formosa, in north-west and eastern Polynesia and in New Zealand, Mr. Whitmee regards as having sprung from one stock which had its home in the Indian Archipelago or the Malacca peninsula. For this family he wishes to retain Baron von Humboldt's name, Malayo-Polynesian; not because it is the best possible name, but because it is in use and well understood.

There are five branches of this family: I. Mr. Whitmee believes the first branch which broke off from the parent stock was that which went across the Pacific to Eastern Polynesia and New Zealand. These people probably retain more of the primitive condition of the parent stock than the others, owing to their isolation. But it is almost certain they have to some extent deteriorated from that condition. This race, which does not now possess a satisfactory collective name, he proposes to call Sazaióri : this word being compounded from the following representative names, $S a$-moa, Hazvai-i, and Ma-ori, following the precedent of the Horsoks of North Thibet, whose name is from Hor pa and Sok-pa. 2. A much later migration went westward to Madagascar, and these people bear the appropriate name Malagasy. Probably an approximate date of this migration may be fixed by the presence of a few Sanscrit words in the Malagasy language. 3. Mr. Whitmee is unable to express any opinion as to when the Formosan migration took place. 4. The latest exodus from the Indian Archipelago was doubtless that which went to north-west Polynesia (Melanesia). For these people he proposes the name Tárapon, from Tárawa, in the Gilbert group (used by Mr. Horatio Hall for the language of that archipelago) and Pónape, a representative atoll of the Caroline group. 5. For that branch of the family found still in the Indian Archipelago he proposes to use the generic name Malayan. He believes all these people may be included under this term, and that the differences which exist between them may be accounted for by the isolation of some, while others have had a greater mixture of foreign blood, and have been more in contact with external culture and other influences which have changed them since the family has been broken up.

At the easte: $n$ end of New Guinea there are mixed people, who may be called sub-Sawaióri, or sub-Malayan, as their affinities with one or other of these divisions may hereafter prove to be.

The following table shows in coinpact form the divisions proposed by Mr. Whitmee :-

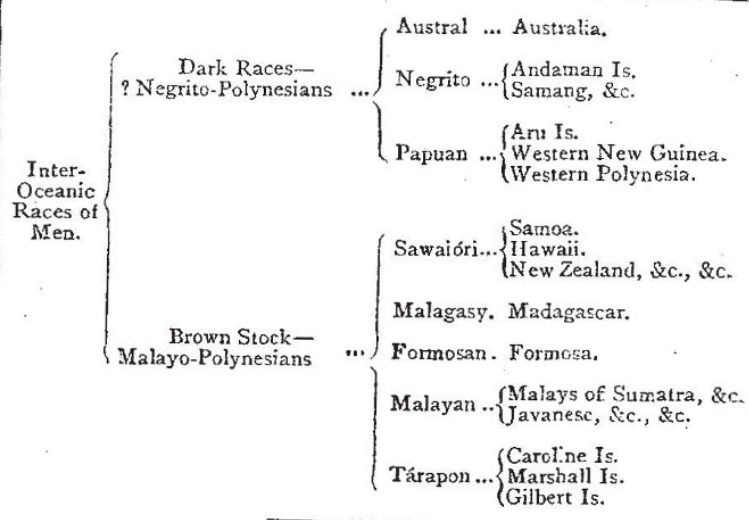

A lively discussion followed, in which Mr. Wallace, Prof. Flower, and Mr. A. H. Keane took part; the two former, while approving of some of Mr. Whitmee's proposed changes, preferred, on the whole, to utilise existing terms. Mr. Keane, in the main, supported Mr. Whitmee's conclusions; indeed, Mr. W'hitmee acknowledged his indebtedness to Mr. Keane for several important suggestions contained in his paper.

The second paper, by the Rev. W. G. Lawes, recently returned from a three years' residence at Port Moresby, New Guinea, was an extremely interesting series of ethnological notes on the Motu, Koitapu, and Koiari tribes of New Guinea.

It is extremely important that all statements about New Guinea should be specific as to locality. It is even more important with reference to the people than to the country, the diversities of race and tribe are so numerous. Twenty-five different dialects and languages are spoken, to the writer's knowledge, in the 300 miles of coast extending from Yule Island to China Straits. Port Moresby is the centre of the Motu district, and is in lat. $9^{\circ} 30^{\prime} \mathrm{S}$. and long. $147^{\circ} 10^{\prime} \mathrm{E}$. The Motu were fully described by Dr. W. Y. Turner in a paper published in the Fournal of the Institute, May, 1878 . So far as the Motu is concerned Mr. Lawes' paper was simply supplementary.

Great importance is attached among the Motu to the tattooing of the women as a means of enhancing beauty. No importance seems to be attached by them to the pattern. The men are sometimes slightly tattooed, but with them it is a decoration of honour, and shows that the wearer has killed some one.

The taboo system of Polynesia is practised on many occasions and for many purposes.

The spirits of the departed go away to ocean space (their hades), and ultimately find their way to the place which is associated in the native mind with plenty and animal enjoyment.

The legend of the Motu respecting the origin of fire is that smoke being seen out to sea, the animals assembled and volun. teered to fetch it. The snake, bandicoot, bird, and kangaroo, all started, but came back without it. The dog then went, and succeeded.

The Koitapu are now for the most part to be found living at one end of the Motu villages although preserving their distinctness and separateness. They are also to be found in little groups of a few houses a little way inland, on a hill overlooking the sea all through the Motu district. The typical Koitapu man is slightly darker in colour than the Motu, and the hair is frizzy, not woolly. The principal differences between the Koitapu and Motu are the following :-

Language. - This is essentially different from the Motu and coast tribes. In a vocabulary of 250 words there are only 12 words which have any affinity for coastal or Malayo-Polynesian dialects.

Food and Cooking. - Their bill of fare is more extensive than the Motu, and the mode of cooking different.

Ornaments.- Those different to the Motu are the breastplate and feather head-dress.

Weapons and Manufactures.--The weapons are stone clubs and spears; the bow and arrow is confined to coast tribes. A netted bag and peculiar kind of matting are made by Koitapu, but the knowledge of pottery is confined to coast tribes.

The Koitapu excel in hunting, but the coast tribes are fishermen. The Motu are the conquerors and superior race, but have a superstitious fear of the Koitapu and inland tribes. The 
Koitapu are supposed to have power to bewitch and cause disease, also to prevent rain from falling.

The Motu take presents to Koitapu in case of disease, and she women sometimes suck the seat of pain in the same manner as described in Sir J. Lubbock's “Origin of Civilisation," pp. 27,28 . There are many indications that the Koitapu are now but a small remnant of what was once a numerous and powerful race.

The Koiari are closely allied to the Koitapu, and inhabit the mountains at the back of the Motu and Koitapu district. They mounsist of a number of scattered tribes. They are physically inferior to the Motu and Koitapu, but more numerous. They are small in stature, dark in colour, and dirty in person. Their bands and feet are remarkably small. Their villages are built on the ridge of a hill. Tree houses are common, almost every village having one at a considerable height. Their language is similar to Koitapu. They cultivate the soil carefully, and are great hunters. The women are more degraded than among the Koitapu or Motu, and polygamy is more common.

The dead are laid out for some weeks in the house, and then exposed to sun and smoke until perfectly dry. When the bones fall apart they are collected and tied up in a bundle and hung up in the deserted house or in a tree close by.

The mode of salutation among the Koiari is peculiar. They salute their friends by chucking them under the chin.

They are great chewers of the betel-nut, and are very eager to obtain salt. They barter their produce occasionally with the Motu at Port Moresby for fish, cocoa-nuts, salt, and pottery.

\section{SCIENTIFIC SERIALS}

Annalen der Physik und Chemie, No. 11, 1878. - In a valuable paper on the passage of the galvanic current through iron, Herr Auerbach describes experiments with reference to the effect of Iongitudinal magnetisation of iron bars or wires on their resistance, and to the extra currents at closing and opening of the circuit, explained by a transverse or circular magnetisation. Circularly magnetic iron conducts a current worse, the stronger the circular magnetisation. The resistance of longitudinally magnetised iron may be less or greater than that of unmagnetic; in the former case the resistance-function has nowhere a minimum or maximum.; the resistance rises steadily from the state of saturated longitudinal, to that of saturated circular, magnetism; and this is realised in hard steel. In the other case the resistance-function has a minimum for the unmagnetic state. Hêrr Auerbach explains the effects observed on the hypothesis of rotatable molecular magnets, and indicates the bearing of his views on them on the fundamental laws of galvanism, and the galvanic constants of iron.- In a third series of experimental magnetic researches, Herr Fromme deals with two modes of magnetising a rod with a spiral conveying a galvanic current. It may be inserted in the spiral after the circuit has been completed, and withdrawn while the current is still flowing; or it may be inserted before the circuit is closed, and withdrawn after it is opened. He now obtains a distinct difference, unperceived before, between the eftects, and the causes of the phenomena are thought to be not of secondary nature (or very little so), but deducible from the essence of magnetism. The results of deducible hoff theory, when the latter of the two above methods is abandoned.-Herr Ritter communicates a first paper of researches on the height of the atmosphere, and the constitution of gaseous on the hel substances. On the two hypotheses of an indifferent state of equilibrium in the atmosphere, and of the oxygen and sitron retaining approximately, in all changes of condition, the properties of a so-called perfect gas, he arrives theoretically at a height of $40 \mathrm{~km}$. for the atmosphere, whereas Schiaparelli's observations make it more than $200 \mathrm{~km}$. He removes this discrepancy by supposing that, in the rise of the air-masses, not only aqueous vapour, but oxygen and nitrogen, pass into the only aqueous vapour, but oxygen and nitrogen, pass into the state of aggregation of a snow-cloud.-Dr. Kolacek studies velocity of propagation of water-waves.

\section{SOCIETIES AND ACADEMIES LONDON}

Royal Society, January 9.- "Note on the Inequalities of the Diurnal Range of the Declination Magnet as recorded at the Kew Observatory," by Balfour Stewart, F.R.S., Professor of
Natural Philosophy in Owens College, Manchester, and William Dodgson.

We are at present engaged in searching for the natural inequalities of the above range, more especially for any of which the period is between 24 and 25 days. We find strong evidence of an inequality of considerable magnitude of which the period is $24^{\circ} \mathrm{\circ}$ days, very nearly. We have also found preliminary evidence of the existence of two considerable inequalities havin periods not very far from $24^{\circ} 65$ and $24^{\circ} 80$ days. These two appear to come together in about II years, but we cannot yet give the exact time of this.

We have not found a trace of any inequality with a period of $24 \cdot 25$ days.

"Some Experiments on Metallic Reflexion," by Sir John Conroy, Bart., M.A. Communicated by Prof. G. G. Stokes, Sec. R.S.

He finds that when light is reflected from a polished surface of gold or copper in contact with various media, the angle of principal incidence diminishes, and the principal azimuth increases with the increase of the refractive index of the medium in contact with the metallic surface; and further, the diminution in the value of the principal incidence appears to be nearly in proportion to the increase of the refractive index of the surrounding medium.

He states that theivalues of these angles for gold with $r \in d$ light are:- -

\begin{tabular}{|c|c|c|c|c|c|c|}
\hline & & & $\begin{array}{l}\text { Principal } \\
\text { Incidence. }\end{array}$ & & & $\begin{array}{l}\text { Principal } \\
\text { Azimuth. }\end{array}$ \\
\hline & & $\ldots$ & & $\cdots$ & $\ldots$ & \\
\hline or ... bisulp & & $\cdots$ & 7246 & $\ldots$ & $\cdots$ & 3623 \\
\hline & & & 7003 & $\ldots$ & $\ldots$ & $364^{8}$ \\
\hline
\end{tabular}

Assuming that the angle of principal incidence for a metal is the same as the angle of polarisation of a transparent substance, that is the angle whose tangent is equal to the refractive index, the value of that angle in air, as deduced from the measurements made in water and carbon bisulphide by multiplying the tangent of the principal incidence in those media by their refractive indices is 76.53 and $77^{\circ} 22$ instead of 76 .

"Researches on the Absorption of the Ultra-Violet Rays of the Spectrum by Organic Substances," by W. N. Hartley, F.Inst. Chem., F.R.S.E., F.C.S., Demonstrator of Chemistry, King's College, London, and A. K. Huntington, F. Inst. Chem., A.R.Sc. Mines, F.C.S. Communicated by Prof. G. G. Stokes, Sec.R.S.

The following were the conclusions reached :-

I. The normal alcohols of the series $\mathrm{C}_{n} \mathrm{H}_{2 \mathrm{n}}+{ }_{1} \mathrm{OH}$ are remarkable for transparency to the ultra-violet rays of the spectrum, pure methylic alcohol being as nearly so as water.

2. The normal fatty acids exhibit a greater absorption of the mare refrangible rays of the ultra-violet spectrum than the normal alcohols containing the same number of carbon-atoms.

3. There is an increased absorption of the more refrangible rays corresponding to each increment of $\mathrm{CH}_{2}$ in the molecule of the alcohols and acids.

4. Like the alcohols and acids, the ethereal salts derived from them are highly transparent to the ultra-violet rays, and do not exhibit absorption-bands.

In order to ascertain whether isomeric bodies exbibited similar or identical absorption-spectra, a series of benzene derivatives was examined. From the great absorptive power of this class of substances it was found necessary to use very dilute solutions, even though the cells holding the liquids were not more than 0.75 inch in thickness. Curves were plotted by taking the proportions of substances in solution as ordinates, and the position of absorption-bands as abscissæ, and these curves are highly characteristic features of very many compounds. About twenty diagrams have thus been made.

The following is a summary of the chief points of interest appertaining to benzene and its derivatives:-

$x$. Benzene, and the hydrocarbons, the phenols, acids, and amines derived therefrom, are remarkable firstly, for their powerful absorption of the ultra-violet rays; secondly, for the absorption-bands made visible by dissolving them in water or alcohol, and diluting; and thirdly, for the extraordinary intensity of these absorption-bands, that is to say, their power of resisting dilution.

2. Isomeric bodies, containing the benzene nucleus, exhibit widely different spectra, inasmuch as their absorption-bands vary in position and in intensity. 